\title{
ESCOLARIZAÇÃO DA LITERATURA: UM OLHAR PARA AS PRÁTICAS ESCOLARES
}

\section{LITERATURE SCHOOLING: A LOOK AT SCHOOL PRACTICES}

\author{
Maria Aparecida Lopes ROSSI ${ }^{1}$
}

\begin{abstract}
Resumo: O presente artigo problematiza dados de pesquisa realizada com o objetivo de discutir a escolarização dos diferentes gêneros de textos no $5^{\circ}$ e $6^{\circ}$ anos do Ensino Fundamental (ROSSI, 2010), observada nas práticas de professores de escola pública. No corpo do artigo, serão discutidas a escolarização de fábulas e uma crônica literária. Inicialmente será feita uma discussão sobre o conceito de escolarização, seguida da problematização do termo escolarização da literatura e, após, serão abordadas as práticas de sala de aula observadas. Na problematização dos conceitos de escolarização e de escolarização da literatura, a discussão se pauta em Soares (2003, 2006), Saraiva (2001) Arena (2010), Zilbermann (1987), Miguez (2003) e Batista (2004). A escolarização é aqui entendida como o resultado da submissão de um determinado conhecimento ao ensino escolar. No que se refere à escolarização da literatura, entende-se, como Miguez (2003), que a leitura da literatura não deve ser entendida e manipulada como uma tarefa escolar, mas sim como experiência estética que se manifesta no prazer de ver, ler e descobrir o mundo através da literatura. Os resultados mostram o que Soares (2003) considera escolarização inadequada da literatura pela escola, quando a leitura dos textos não é direcionada para os recursos de expressão utilizados ou para a percepção do uso estético da linguagem e nem tampouco para a compreensão da visão de mundo e do contexto em que se inserem.
\end{abstract}

Palavras-chave: Literatura infanto-juvenil. Escolarização. Práticas Escolares. Leitura. Ensino

\begin{abstract}
This paper problematizes research data carried out with the objective of discussing schooling of different genres of texts used in fifth and sixth years of elementary school (ROSSI, 2010), as observed in public-school teachers' practices. Discussions are anchored on schooling of fables and a literary chronicle, departing from the concept of schooling itself, going through the problematization of the term schooling of literature to, finally, approach classroom practices. Discussion of the concepts of schooling and schooling of literature are based on Soares (2003, 2006), Saraiva (2001) Arena (2010), Zilbermann (1987) and Miguez (2003) and Batista (2004). Schooling is here understood as the result of the submission of a certain knowledge to school teaching. Literature schooling is understood as Miguez (2003), who argues that reading of literature should not be understood and manipulated as a school task, but as an aesthetic experience that manifests itself in the pleasure of seeing, reading and discovering the world through literature. Results show what Soares considers inadequate schooling of literature by the school, when reading is neither directed to the expression resources used nor to the perception of the aesthetic use of the language nor to the comprehension of the world view and the context in which they are inserted.
\end{abstract}

Keywords: Children's literature. Schooling. School Practices. Reading. Teaching

\footnotetext{
${ }^{1}$ Professora adjunta da Universidade Federal de Goiás/Regional Catalão. Doutorado em Educação pela UNB. Email: picidarossi@gmail.com
} 


\section{Introdução}

A literatura é entendida por Cândido (2004, p. 74) como direito universal do homem, tanto pelo seu caráter humanizador quanto pelo fato de se constituir em necessidade universal, vez que "ninguém pode passar 24 horas sem mergulhar no universo da ficção e da poesia". Além de se constituir como direito, o papel da Literatura infantil e juvenil como desvendamento de mundo e instrumento de inserção dos sujeitos na cultura escrita vem sendo destacado por vários autores, dentre os quais estão Saraiva (2001), Arena (2010) e Zilbermann (1987).

Para Saraiva (2001, p. 82) os textos literários, sejam de ficção ou poesia, propiciam à criança o encontro com respostas para suas inquietações, vez que, "ao defrontar-se com textos de valor estético e cultural que traduzem o sentido da existência por engendrarem respostas a seus conflitos e emoções, a criança acrescenta um novo estímulo à sua vida”. Por sua vez, Arena (2010, p. 16) salienta o fato de que, na relação com o texto literário, a criança apropria-se da cultura e da história "do homem na terra". Zilberman (1987, p. 22) salienta ainda que, por sintetizar uma realidade, a linguagem literária, por mais diversas que sejam as condições de espaço e tempo em que foi escrita, continua a se comunicar com seu leitor "porque ainda fala de seu mundo, com suas dificuldades e soluções, ajudando-o, pois, a conhecê-lo melhor".

Diante de tais estudos, é quase natural que a escola passe a incorporar, em suas práticas, a leitura da literatura como instrumento para formação do leitor e sua inserção na cultura escrita. Defensora dessa incorporação, Zilberman (2009, p. 35), ao problematizar as relações entre leitura e escola, enfatiza que "o recurso à literatura pode desencadear com eficiência um novo pacto entre os estudantes e o texto, assim como entre o aluno e o professor".

Entretanto, tais práticas têm sido alvo de inúmeras investigações que evidenciam que, na maioria das vezes, o texto literário não é tratado na escola como uma experiência estética da linguagem e como fruição. Pelo contrário, utiliza-se o livro literário como instrumento de manipulação da criança na tentativa de conformá-la ao mundo dos adultos.

O que se percebe em grande número de estudos que visam compreender a escolarização da literatura é que, nas atividades propostas com vistas à leitura do texto, há um apagamento da sua voz e da necessidade de compreensão dessa voz, para se solicitar a opinião do aluno e também fazer com que ele retire algum conhecimento do que foi lido. Nesse processo, percebese o que Batista (2004) diz ser uma característica do processo de escolarização dos textos que devem dirigir e orientar a leitura, 
confunde-se com o aprender - sobre a vida, sobre o país, sobre a leitura e os livros, sobre o que se deve ou não fazer, como se deve ser. (BATISTA, 2004, p. 29)

Assim, visando a contribuir com a discussão sobre a escolarização da literatura nos anos finais do Ensino Fundamental, o presente artigo problematiza dados de pesquisa ${ }^{2}$ realizada com o objetivo de perceber a escolarização dos diferentes gêneros de textos no quinto e sexto anos do Ensino Fundamental (ROSSI, 2010), observada nas práticas de professores de escola pública de uma cidade da região do sudeste goiano. As estratégias metodológicas para coleta e geração de dados, seguindo a tradição da pesquisa qualitativa de caráter etnográfico, foram a entrevista semiestruturada com os professores que trabalham com a Língua Portuguesa no $5^{\circ}$ e $6^{\circ}$ anos do Ensino Fundamental de nove anos em escolas da rede estadual de ensino, e a observação de aulas de Língua Portuguesa em que os professores estavam trabalhando a leitura com textos selecionados por eles, que não passaram por processos de didatização. No escopo deste artigo será discutida a escolarização de fábulas e de uma crônica literária, observada em três aulas. O objetivo é problematizar as atividades de leitura desenvolvidas na escola a partir desses dois gêneros de texto, buscando entender como tais textos são lidos em sala de aula e os motivos que levam o professor a selecionar tais gêneros e não outros, e, ainda, se a presença de diferentes gêneros de texto na sala de aula implica igual diversidade de maneiras de abordá-los

A relevância de tal discussão se ancora no fato de ela contribuir para se entenderem os modos como a escola se apropria da discussão sobre o uso da diversidade de gêneros de texto no ensino da leitura. Com isso, evidencia-se a visão escolar sobre os estudos que colocam a necessidade de o ensino da leitura se organizar em torno da diversidade de gêneros que circulam socialmente, e as práticas pedagógicas que ainda continuam presas a uma cultura escolar que ignora os diferentes objetivos que sugerem a leitura dos diferentes gêneros.

Inicialmente faremos uma discussão sobre o conceito de escolarização, seguida da problematização do termo escolarização da literatura e, após, abordaremos as práticas de sala de aula observadas.

\section{Escolarização da literatura: que caminhos percorrer?}

Ao discutir as relações entre letramento e escolarização, Soares (2003) lembra que o verbo escolarizar exige sempre um complemento que pode ser de duas naturezas distintas: pode

\footnotetext{
${ }^{2}$ Pesquisa de doutorado realizada junto ao Programa de Pós-Graduação em Educação da Universidade de Brasília, intitulada: $O$ processo de escolarização dos diferentes gêneros textuais observado nas práticas de ensino de leitura.
}

Revista Graphos, vol. 21, n 1, 2019 | UFPB/PPGL | ISSN 1516-1536 
designar um ser animado como escolarizar pessoas, ou pode se referir a um conteúdo, que seria escolarizar um determinado conhecimento ou uma prática social. Assim, a autora salienta que:

\footnotetext{
Não só as pessoas são escolarizadas, passam por aprendizado em escola, sendo, nesse e por esse processo, transformadas; também conhecimentos e práticas sociais são escolarizados, passam a objetos de aprendizagem na escola, sendo também eles, nesse e por esse processo, transformados. (SOARES, 2003, p. 93)
}

Nesse processo de transformação, a autora mostra que fora da escola os usos que fazemos da leitura e da escrita atendem a necessidades e interesse pessoais ou de grupos sociais, e acontecem de forma natural ou espontânea. Já na escola, esses usos da língua escrita são planejados e selecionados a partir de objetivos predeterminados, com o intuito de levar os educandos a aprendizagens diversas. Para ela "de certa forma a escola autonomiza as atividades de leitura e de escrita em relação a suas circunstâncias e usos sociais, criando seus próprios e peculiares eventos e suas próprias e peculiares práticas de letramento (SOARES, 2003, p. 107).

Como exemplo dessa transformação, a autora traça um paralelo entre diversos eventos de letramento observados na vida diária e na escola, salientando que, fora da escola, a leitura de um texto literário como um conto ou poema ocorre quase sempre de forma espontânea, atendendo quase que exclusivamente a interesses e preferências do leitor, que pode até abandonar a leitura caso esteja sem tempo ou se sinta desinteressado pelo texto. Já na escola, textos literários estão, na maioria dos casos, reproduzidos em folhas avulsas ou no livro e devem ser lidos integralmente, mesmo que não despertem o interesse no aluno leitor, que acaba não tendo a opção de selecionar o que vai ler. Encerrada a leitura, o aluno deve responder a questões de compreensão, como indicar o ponto de vista do narrador, caracterizar personagens ou numerar estrofes e outras questões do gênero.

Assim, a escolarização é entendida como o processo de ordenar, através de organização e sequenciação de tarefas, organização dos alunos em categorias, organização do tempo em unidades de ensino, divisão dos saberes em áreas e disciplinas. Ou seja, é o resultado da submissão de um determinado conhecimento ao ensino escolar. Nesse sentido, entende-se, como Soares, que a escolarização é inevitável porque "é da essência da escola a instituição de saberes escolares que se constituem pela didatização ou pedagogização de conhecimentos e práticas culturais" (SOARES, 2006, p. 47).

Entretanto, ao fazer um estudo da escolarização do livro literário que é perpetrada pelo livro didático, essa autora considera que tal escolarização nem sempre é adequada, já que em muitos casos ela "deturpa, falsifica, distorce a literatura, afastando, e não aproximando, o aluno 
das práticas de leitura literária, desenvolvendo nele resistência ou aversão ao livro e ao ler" (SOARES, 2006, p. 47). Essa é também a posição de autores como Miguez (2003) e Zilberman $(2009,1987)$ que criticam a presença do texto literário na escola na forma como essa presença normalmente acontece: transformada em atividades de caráter mecânico e limitador dos sentidos do texto, reduzido, muitas vezes, a um número restrito de observações classificadas como certas.

Para Soares (2006), uma escolarização adequada seria a que levasse às práticas de leitura literária que ocorrem fora do contexto escolar, voltadas para a apreciação da literariedade do texto. Ou ainda, como salienta Zilberman, para cumprir sua tarefa de modo integral no que diz respeito à formação do leitor, a escola necessita entender o significado da leitura:

\footnotetext{
Como procedimento de apropriação da realidade, bem como o sentido do objeto por meio do qual ela se concretiza: a obra literária. Pois, acreditando que o ato de ler, em decorrência de sua natureza, se reveste de uma aptidão cognitiva, esta só se complementa na companhia do texto que demanda seu exercício. (ZILBERMAN,2009, p. 30)
}

Deste modo, pode-se concluir com Miguez (2003, p. 31) que a leitura da literatura não deve ser entendida e manipulada como uma tarefa escolar. Pelo contrário, deve ser vista como experiência estética que se manifesta no prazer de "ver, ler e descobrir o mundo através da literatura". Ou seja, ao levar o livro literário para ser lido por alunos, é salutar que o professor leve o leitor iniciante a dialogar com a realidade que se descortina na história, levando-o a desfrutar dos mundos e das vivências que a obra sugere e, partir desta experiência, lance novos olhares para entender a sua própria realidade.

\section{0 texto escolarizado}

Durante a investigação que fundamenta a presente discussão e que teve como um dos objetivos problematizar a escolarização da leitura literária, o gênero mais presente nas práticas de sala de aula observadas foi a fábula, que figurou em três aulas, duas do sexto ano e uma do quinto ano de duas escolas da rede estadual de ensino, ambas situadas em bairros periféricos da cidade que atendem alunos oriundos de famílias de baixo poder aquisitivo. A opção por realizar a pesquisa nos $5^{\circ}$ e $6^{\circ}$ anos do Ensino Fundamental de nove anos, nas escolas da rede estadual que oferecem as duas séries foi por entender que, nessa etapa da escolarização, o $5^{\circ}$ e o $6^{\circ}$ anos correspondem às antigas $4^{\mathrm{a}}$ e $5^{\mathrm{a}}$ séries que marcavam, respectivamente, o final da fase inicial do ensino fundamental, quando o aluno deveria estar completando o processo de alfabetização, 
e o início da segunda fase dessa etapa do ensino, quando se espera que o aluno tenha alcançado habilidades para um uso eficaz da língua oral e escrita que lhe possibilite continuar a progredir até o final do Ensino Fundamental. Segundo os Parâmetros Curriculares Nacionais de Língua Portuguesa (1997), a antiga $5^{\mathrm{a}}$ série e atual $6^{\circ}$ ano constitui o segundo gargalo da escola, concentrando a repetência devido às dificuldades em se garantir o aprendizado da leitura e escrita de forma eficaz.

O que se pode observar é que, nas três aulas observadas, as atividades realizadas foram bastante semelhantes, havendo a preocupação de levar o aluno a identificar as características do gênero fábula, sempre definido como uma história que ao final quer passar uma moral, e o pedido para que os alunos, ao final da leitura, façam um reconto oral da história e também que identifiquem e comentem a moral percebida no texto. O que diferenciou uma abordagem da outra foram as atividades que finalizaram o trabalho com a fábula.

$\mathrm{Na}$ sala do $6^{\circ}$ ano a professora utilizou o livro Alguns Contos da América do Sul, (PAULUS, 2003), que fazia parte do acervo da biblioteca da escola e foi distribuído para os alunos divididos em duplas. Os alunos foram orientados a ler o último texto do livro: A Onça e $o$ Veado. Antes da leitura, os alunos foram orientados pela professora a ler o texto buscando descobrir qual seria a moral da história. Após a leitura do texto os alunos foram indagados por meio de questões orais como:

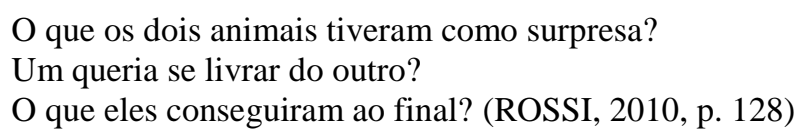

São perguntas objetivas que indagam sobre o que está exclusivamente no texto, o que Marcuschi (2005) chama de pura decodificação. Ao final da atividade, os alunos demonstram compreensão do desenvolvimento da trama lida e da moral que a fábula encerra. Aproveitando ainda o livro que os alunos têm em mãos, a professora pede que as duplas escolham uma outra história, que deve ser lida em silêncio porque depois todos deverão explicar para o restante da turma qual foi a moral da história lida. Um fato curioso é que, apesar de o livro ter cinco histórias, quase todas as duplas escolheram a mesma: "Os olhos da onça". Quando a professora comenta a coincidência, um dos alunos explica que a história foi a preferida pela maioria por ser a que tinha menor número de páginas.

O fato é revelador de como o tamanho do texto influencia as escolhas de alunos e professores. É ainda um indício de uma das características do letramento escolar que é 
determinado também pelo tempo das aulas, e, na medida em que o professor opta por trabalhar textos mais curtos, vai criando essas preferências também nos alunos.

Ao final da leitura feita pelos alunos a professora pediu às duplas que recontassem o texto lido. O reconto é feito por uma dupla de alunos que se oferece para realizar a tarefa. Os alunos recontam a história de uma forma bastante resumida, atendo-se apenas ao núcleo central da história. A professora pede que outros alunos que leram o mesmo conto acrescentem mais alguma coisa ao reconto feito pela primeira dupla. Os alunos fazem basicamente o mesmo relato. A professora argumenta que não é necessário que as duplas repitam o que já foi objeto de reconto por outros alunos, que os demais podem fazer acréscimos ao que já foi dito.

Entretanto, as questões feitas pela professora também não são direcionadas para os pormenores da história ou para a apreciação de sua literariedade. As perguntas são direcionadas para os alunos comentarem sobre os personagens ou destacarem a parte da história que mais gostaram. Acontecendo aqui, o que Marcuschi (2005) classifica de perguntas vale-tudo, que, conforme ressalta, "são as perguntas que indagam sobre questões que admitem qualquer resposta, não havendo possibilidade de se equivocar. A ligação com o texto é apenas um pretexto sem base alguma para a resposta.” (MARCUSCHI, 2005, p. 55) Outro aspecto a ser destacado na escolarização dos textos é que as atividades não são direcionadas para a percepção dos recursos de expressão utilizados e do uso estético. Tais atividades se voltam principalmente para os conteúdos dos textos, esquecendo-se da recriação que deles faz a literatura. (SOARES, 2006)

Em outra aula observada nesta mesma turma a professora levou para a sala de aula duas versões da fábula "A cigarra e a formiga", atribuída a Esopo e recontada por Jean de La Fontaine, escritas por Monteiro Lobato: "I A formiga boa"; "II A formiga má". Ela inicialmente retomou o conceito de fábula com os alunos, lembrando que esses textos se caracterizam por trazer ensinamentos e exemplos de vida.

A professora levou para a sala apenas duas cópias dos textos, sem referências de data ou da obra da qual foram retirados, e pede a dois voluntários que façam a leitura. Após uma aluna fazer a leitura de "A formiga boa", a professora enfatiza: Esta foi a formiga boa. Ela acolheu a cigarra? Acolheu, não foi? Agora vamos ouvir a formiga má.

Após outro aluno realizar a leitura da segunda versão da fábula, a professora indaga qual o ensinamento deixado pelas fábulas. Todos os alunos respondem que a moral da história é que as pessoas devem sempre ser boas e nunca fazer o mal. Após a breve conversa com os alunos sobre a moral das histórias lidas, a professora passa a explicar que os alunos deverão criar um 
diálogo entre a formiga boa e a má, falando sobre a cigarra. Ela lembra aos alunos que inicialmente eles devem dar um título para o diálogo e atentarem para os usos do travessão, necessários para a escrita do diálogo, e dos sinais de pontuação.

Conforme explicou ao final das atividades, o objetivo da professora com a leitura das duas versões da fábula foi, além de mostrar uma outra versão da fábula, uma vez que os alunos só conheciam a formiga má, também enfatizar o uso dos sinais de pontuação, mostrar que qualquer profissão é importante e salientar a distinção entre o bem e o mal.

$\mathrm{O}$ que se percebe, aqui, é o texto sendo utilizado para levar o leitor a adquirir conhecimentos sobre a língua, no caso os sinais de pontuação, e a preocupação em retirar dele valores a serem seguidos. As atividades realizadas após a leitura do texto não levam em conta o texto lido e tampouco precisam ser validadas por sua leitura, mesmo porque, vale ressaltar que os alunos só tiveram acesso aos textos a partir das leituras feitas pelas duas alunas, já que, conforme explicou a professora, não havia cópias para toda a turma.

O outro trabalho com fábulas foi feito numa sala do $5^{\circ}$ ano que contava no dia com 26 alunos presentes. Nesse caso, os alunos não tiveram acesso ao livro; a fábula foi lida pela professora para a turma. O trabalho realizado na aula observada foi a complementação, conforme explicou a professora, de um trabalho com fábulas que estava sendo feito há cerca de vinte dias. Durante esse tempo, todos os dias era lida uma fábula que, posteriormente, era alvo de comentários. No total foram lidas cinco fábulas para os alunos, retiradas do livro Fábulas de Esopo. Dentre as fábulas lidas destaca-se aqui: “A menina do leite”. Após a leitura do texto, os alunos responderam oralmente a questões que tinham por objetivo levá-los a reconstituir a história de acordo com a sequência em que os fatos são relatados. Assim foram formuladas questões como:

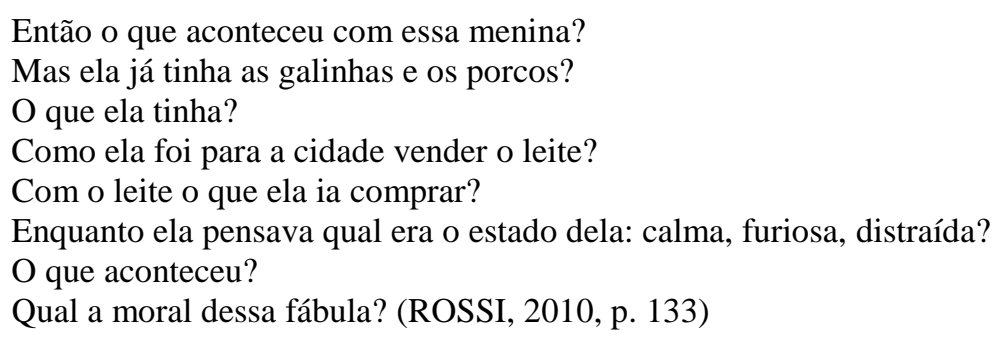

Ao final das atividades orais, a professora entrega para os alunos atividades escritas, num total de oito questões, que devem ser respondidas em casa e depois entregues para a professora. As questões são variadas: a primeira é voltada para a definição de fábula; nas quatro seguintes o professor busca levar os alunos a recuperar informações gerais sobre as fábulas lidas 
com o auxílio de charadas, ilustrações de personagens e um diagrama; uma outra questão é voltada para o reconhecimento e fixação de tempos verbais, outra procura trabalhar a produção escrita do aluno a partir da paráfrase de uma das fábulas lidas, e a última procura trabalhar o entendimento dos alunos sobre o que são considerados "ensinamentos", retirados das fábulas.

O que se pode inferir nesses episódios de escolarização das fábulas na escola, é que as atividades realizadas se organizam em basicamente três categorias: a recuperação dos elementos literais e explícitos do texto; o uso do texto para trabalhar nomenclatura gramatical e, por último, o texto como instrumento para inculcar nos leitores valores morais caros ao mundo adulto.

Nesse aspecto, observa-se a preferência da escola em trabalhar as fábulas, gênero de texto que se caracteriza pelos fins educativos, voltados para cultivar no leitor valores e atitudes que a sociedade espera que ele adote e que devem ser cultivados no espaço escolar. Como afirma Kleiman (2001), é a herança da tradição escolástica no trabalho com a interpretação de textos que se transformou em método para preservar e inculcar valores tidos como socialmente aceitáveis e moralmente corretos.

No processo de escolarização da literatura, observou-se ainda o uso de uma crônica para ser trabalhada em várias disciplinas com atividades denominadas de interdisciplinares pelo professor. Foi o observado com a leitura da crônica intitulada "Fábula", de Luís Fernando Veríssimo, que foi entregue aos alunos em uma folha xerocada, retirado da revista Veja, da Editora abril, sem referência de data. As atividades realizadas com este texto, segundo relato da professora, tiveram primeiro o objetivo de levar os alunos a identificarem as características do texto, conduzindo-os a caracterizá-lo como crônica. Após essas atividades, que foram feitas oralmente, a professora explica que passou a trabalhar o texto voltado para o conteúdo de ciências com foco nas formas de conservação dos alimentos, origem dos alimentos e alimentação saudável. Depois, a leitura do texto serviu ainda de ponto de partida para uma discussão dentro da aula de geografia sobre democracia, direito de voto e as escolhas que são feitas com base na opinião da maioria.

Como se pode perceber, o texto propriamente dito só foi focalizado no que dizia respeito à identificação das suas características como pertencendo ao gênero crônica, o que foi feito na medida em que era comparado com outros gêneros, como a notícia. No entanto, o principal objetivo do trabalho com o texto foi utilizá-lo para trabalhar conteúdos de ciências e geografia. Não se percebe, neste caso, a realização de estratégias de leitura que levem ao processamento do texto pelos alunos, que os façam perceber os efeitos de sentido criados pelo autor quando 
ele usa palavras de duplo sentido para relacionar as características dos alimentos como as atitudes que tomam contra o peixe estragado, provocando humor e ironia. É o que se verifica, por exemplo, no trecho:

Os embutidos, ensimesmados, não diziam nada, mas o presunto, que não tinha qualquer sofisticação, que era um cru, murmurava palavrões. (trecho da crônica "Fábula", VERÍSSIMO, s/d)

Para entender estes efeitos, o leitor teria que fazer inferências a partir de seu conhecimento prévio, tanto sobre o que sejam alimentos embutidos e o duplo sentido dado à palavra, quando o autor adjetiva esses alimentos com a palavra ensimesmados, quanto sobre um tipo de presunto que é o cru, percebendo o duplo sentido dado à palavra opondo-a à palavra sofisticação. Vale ressaltar aqui que a inferência é citada por vários estudiosos da leitura como o processo de construção do significado onde o leitor ativa seu conhecimento para resgatar informações que não estão explícitas na superfície do texto. As inferências são determinadas pelo contexto social e cultural a que cada indivíduo pertence e, dessa forma, ao se ler o implícito no texto, integram-se os dados à própria experiência de mundo do leitor de acordo com a cultura em que está enraizado (DELL ISOLA, 1988)

Na leitura do texto "Fábula", os alunos de escola pública, normalmente oriundos de famílias de baixo poder aquisitivo, teriam que realizar o que Bortoni-Ricardo (2005) classifica de uma experiência de comunicação transcultural, uma vez que muitos dos termos usados no texto e vários dos alimentos citados, e suas características, não fazem parte da realidade das famílias de baixa renda. Nessa experiência, o papel do professor surge como de fundamental importância para levar os alunos a captar os efeitos de humor produzidos no texto que explora a ambiguidade de sentidos de muitas palavras e rompe com a previsibilidade do tema enfocado pela crônica.

Nesse caso, poderia ser exemplo de pistas de contextualização levar os alunos a relacionar o título da crônica, "Fábula", com as características do gênero fábula, que normalmente dota de traços animados e humanos, objetos e animais. Além disso, as estratégias de leitura adotadas teriam que levar o aluno a perceber os textos com os quais "Fábula" intertextualiza de forma implícita, através de um jogo de palavras que produz humor e ironia. É o caso da afirmação:

Todos protestavam contra o peixe, que já estava pra lá de escabeche e obviamente ultrapassara todos os graus de tolerância dos seus convivas dentro daquele espaço apertado. (Autor, 2010, anexo 15) 
Para entender essa passagem o aluno/leitor teria que relacioná-la a um trecho de letra de música interpretada por Caetano Veloso: "Você já está pra lá de Marrakesch", percebendo a semelhança sonora e o jogo de sentidos que o autor provoca, evocando na palavra escabeche o termo usado na música, marrakesch, para significar que o peixe está passado, perdido. Essa é uma operação que exige que o leitor ative seu conhecimento enciclopédico ou conhecimento de mundo, essencial para a produção de sentido da crônica.

Como esse, vários outros trechos da crônica exigem um intenso trabalho de ativação de conhecimentos prévios e realização de inferências para serem compreendidos. Através de comentários, prefácio a perguntas, reelaborações e paráfrases, o leitor em formação deve ser levado a perceber o deslocamento de sentidos operado pelo autor com vários termos, como é o caso de ensimesmado, característica atribuída aos alimentos embutidos, num jogo de palavras que, ao mesmo tempo que remete a um tipo de alimento, joga também com outro significado para a palavra, evocando aquele que é fechado em si mesmo, calado, daí o adjetivo: ensimesmado.

No desenvolvimento do texto todos os alimentos citados são adjetivados com termos usados com duplo sentido, que, ao mesmo tempo que remetem a uma característica da composição do alimento, remetem também ao processo de identificá-los com traços animados e humanos. É o caso de: leite desnaturado; garrafa de mineral - mal-humorada - problemas de gases; abobrinhas entretidas numa conversa interminável; manteiga e ovos, moles por dentro, e assim por diante. É este jogo de palavras que evoca a ambiguidade de sentidos que chama atenção no texto e confere humor à crônica. Para entendê-lo o leitor teria que se valer de um modelo cognitivo, baseado em conhecimentos armazenados na memória num intenso processo de preenchimento de lacunas e realização de inferências, interagindo com o autor na construção de sentidos do texto.

Para o leitor ainda em formação, operações como essa têm que ser facilitadas por pistas de contextualização fornecidas pelo professor, mediador da construção da leitura do texto pelo aluno. Essa mediação, que não deve ser apenas um veredicto sobre a validade ou não das tentativas de leitura feitas pelos alunos, constitui oportunidades de conduzi-los a novas formas de pensar, de analisar, de categorizar e de falar, que lhes permitirão atingir um grau de compreensão que os ajudará a solucionar problemas de leitura em situações análogas às que já foram vivenciadas. 


\section{Algumas considerações}

A escolarização dos textos literários discutida no corpo deste artigo aponta para algumas características da tradição escolar ainda muito presentes nas práticas de sala de aula. A primeira delas é que, no processo de seleção dos textos a serem trabalhados, a literariedade não é o principal critério de escolha dos textos. A principal motivação para a seleção de texto é o seu conteúdo e a possibilidade de ele servir para: a veiculação de conteúdos escolares relativos ao ensino da língua, como usos de sinais de pontuação ou identificação de classes de palavras; a inculcação de valores morais nos alunos, ou ainda para trabalhar textos que possam ser aproveitados para outras disciplinas, no que as professores chamam de trabalho interdisciplinar. Esta foi a motivação apresentada principalmente por professores que atuam no $5^{\circ}$ ano, quando trabalham todas as matérias com a turma, e não apenas língua portuguesa.

Outra característica é que os textos sofrem transformações de sentido nesse processo de inserção nas práticas escolares, vez que as práticas de leitura são direcionadas, na maioria das vezes, para fins didáticos e pedagógicos, e nem sempre focalizam o prazer estético e a visão de mundo vislumbrada pela obra.

Desta forma, o que se observa é o que Soares (2003) considera escolarização inadequada da literatura pela escola, quando a leitura dos textos não é direcionada para os recursos de expressão utilizados ou para a percepção do uso estético da linguagem, e nem tampouco para a compreensão da visão de mundo e do contexto em que se inserem, como se observou na leitura do texto "Fábula", de Veríssimo.

Deste modo, o que se evidencia é que mudar esse quadro de escolarização inadequada da literatura implica tornar a escola um espaço de discussão e construção de conhecimentos. Tal transformação não pode ficar só a cargo dos professores, mas, principalmente, dos responsáveis pela educação em todos os níveis de ensino, fomentando programas de formação continuada que permitam ao professor um estudo acurado das teorias que fundamentam a relação escola e literatura, para que eles tornem-se sujeitos de práticas de ensino formadoras que possibilitem aos educandos uma visão mais ampla tanto de si próprios como da realidade que os cerca, possibilitada pela leitura da literatura.

\section{Referências}

ARENA. A literatura infantil como produção cultural e como instrumento de iniciação da criança no mundo da cultura escrita. In: SOUZA, R. J. de (Org.). Ler e compreender: estratégias de leitura. Campinas, Mercado de Letras, 2010, p. 13-44. 
BATISTA, Antônio Augusto Gomes. O texto Escolar: uma história. Belo Horizonte: Autêntica, 2004.

BORTONI-RICARDO, Stella Maris. Nós cheguemu na escola, e agora? São Paulo, Parábola, 2005.

CANDIDO, Antonio. Vários Escritos. São Paulo/Rio de Janeiro: Duas Cidades/Ouro Sobre Azul, 2004.

DELL ISOLA. Regina Lúcia P. Leitura: inferência e contexto sócio-cultural. Belo Horizonte: FALE/UFMG, 1991.

KLEIMAN, ÂNGELA (org). A Formação do Professor: Perspectivas da Linguística Aplicada. Campinas, SP: Mercado de letras, 2001.

MARCUSCHI, Luiz A. Compreensão de texto: algumas reflexões. In. DIONÍSIO, Ângela Paiva e BEZERRA, Maria Auxiliadora (org). O Livro didático de Português: múltiplos olhares. Rio de janeiro: Lucerna, 2005.

MIGUEZ, Fátima. Nas Arte-Manhas do Imaginário Infantil: O lugar da Literatura na Sala de Aula. Rio de Janeiro: Editora Zeus, 2003.

ROSSI, Maria Aparecida Lopes. O processo de escolarização dos diferentes gêneros textuais observado nas práticas de ensino de leitura. 2010. 249 f. Tese. Faculdade de Educação, Universidade de Brasília, Brasília, 2010.

SARAIVA, Juracy Assmann (org). Literatura e Alfabetização: do plano do choro ao plano da ação. Porto Alegre: Artmed Editora, 2001.

SOARES, Magda. Letramento e escolarização. In: RIBEIRO, Vera Masagão (org).

Letramento no Brasil. São Paulo:Global,2003.

A Escolarização da Literatura Infantil e Juvenil. In EVANGELISTA. Aracy A.M. BRANDÃO, Heliana M. B. e VERSIANI. Zélia M (orgs). A escolarização da Leitura Literária: O jogo do livro infantil e Juvenil. $2^{a}$ ed. Belo Horizonte: Autêntica, 2006.

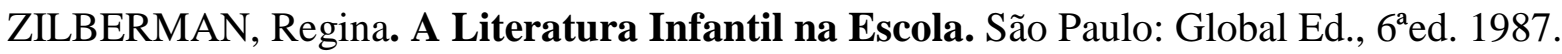

Recebido em: 05/02/2019

Aceito para publicação em: 14/03/2019

Revista Graphos, vol. 21, n 1, 2019 | UFPB/PPGL | ISSN 1516-1536 